\title{
DECROLY E PIAGET - EM BUSCA DE ALGUMAS APROXIMAÇÕES
}

\author{
DECROLY AND PIAGET - LOOKING FOR SOME SIMILARITIES
}

Ana Maria Ferreira Lemes Stafusa ${ }^{1}$

\begin{abstract}
Resumo
Este artigo tem como tema Decroly e sua metodologia global dos centros de interesses e a teoria de Piaget, tendo os dois autores em comum a formação em biologia e psicologia. Ambos estudaram a criança e seu aprendizado e/ou como aprendem. Um dos objetivos deste estudo é identificar alguns entrelaçamentos desses dois personagens que, em suas épocas, abordavam a educação de forma nada tradicional e, também, o ensino e suas peculiaridades no plano de pedagogia experimental. Foram tomados como referência livros da Coleção Educadores. Apresentaremos, inicialmente, uma breve biografia de Decroly e Piaget, em seguida, de modo resumido, adentraremos em suas questões de estudo e, finalmente, apontaremos alguns aspectos das possíveis aproximações entre suas pesquisas e/ou metodologias.
\end{abstract}

Palavras-chave: Decroly. Piaget. Centros de interesse. Ensino. Aprendizagem

\begin{abstract}
This paper has as its theme Decroly and his global methodology of interest centers and Piaget's theory, they have in common a background in Biology and Psychology. Both studied the child and his learning and/or how they learn. We discuss some similarities of these two characters who, in their times, approached education in a non-traditional way, and teaching and its peculiarities in the plane of experimental pedagogy. Books from the Coleção Educadores were taken as reference. Firstly, we present a brief biography of Decroly and Piaget, in a summarized way, their study questions, and finally we indicate some aspects of the possible similarities between their researches and/or methodologies.
\end{abstract}

Keywords: Decroly. Piaget. Centers of interest. Teaching. Learning

\footnotetext{
${ }^{1}$ Mestranda do Programa de Pós-Graduação em Ensino na Educação Básica da Universidade Federal do Espírito Santo. E-mail: amflemes@gmail.com
} 
Decroly e Piaget - em 6usca de algumas aproximações

\section{Introdução}

Navegando pelos mares do ensino, dentro do processo de formação e constituição dos saberes cognitivos da criança, encontramos Decroly e Piaget. Esses dois, psicólogos e biólogos, enveredaram em caminhos pouco ortodoxos para a época em que viveram, em busca de respostas para suas teorias, em meio a processos experimentais, dedicando suas vidas nesse intento.

O presente artigo é um recorte de uma pesquisa preliminar na qual se buscou identificar algumas aproximações entre os trabalhos de Decroly e Piaget, fruto de minhas investigações, analisando suas teorias. O estudo foi desenvolvido, tomando como referências Francine Dubreucq (2010) e Sylvain Wagnon (2009), no que diz respeito a Decroly e, Alberto Munari (2010), relativamente a Piaget, autores que tratam desses personagens nos livros da série Coleção Educadores, organizada pelo MEC.

No texto, apresentam-se, primeiramente, alguns dados biográficos de Decroly e Piaget; em seguida, suas produções e suposições relacionadas à educação das crianças e, finalmente, possiveis aproximações e tangenciamentos entre elas.

\section{Decroly e Piaget: breves dados biográficos}

Segundo Francine Dubreucq ${ }^{2}$ (2010), Jean Ovide Decroly, foi um médico, biólogo e psicólogo belga nascido em Rennaix em 23 de julho de 1871, tendo falecido em Uccle em 12 de setembro de 1932.

Decroly, sempre avesso às aulas tradicionais e de cunho religioso, foi expulso de muitas escolas. Graduou-se em medicina pela Universidade de Gand, em 1896. Em 1898, se tornou assistente em neurologia do Dr. Glorieux, na policlinica de Bruxelas, a mesma cidade onde fixou resi-

\footnotetext{
${ }^{2}$ Diretora do Centro de Estudos Decrolianos e da Biblioteca Sociopedagógica Dr. Decroly, em Bruxelas. Anteriormente foi professora e, depois, diretora da escola Decroly-I'Ermitage de Bruxelas (1952-1983).
} 
dência. Em 1901, fundou a escola École d'Enseignement Spécial pour Enfants Irreguliers ${ }^{3}$, onde trabalhou o seu método global, que vai do todo para as partes, indo do caos à ordem. Toda sua vida foi dedicada a estudar sua metodologia e aprimorá-la. Recebeu o título de professor de Pedagogia da cidade de Bruxelas em 1912.

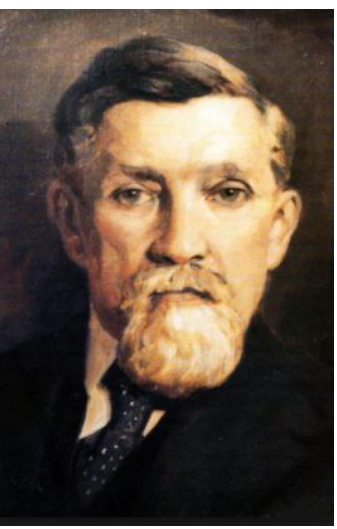

Figura 1 - Jean Ovide Decroly

Fonte: https://grandespensadoress.wordpress.com

Decroly escreveu aproximadamente 39 obras, sendo algumas delas em coautoria, dentre as quais, destacamos as seguintes:

- 1904 - La Médico-pedagogie e Les enfants anormaux au point de vue mental5;

- 1920 - Semiologia da psicológica da afetividade e particularmente da afetividade infantil, em coautoria com G. Vermeylen;

- 1921 - Vers I'écolle rénovée;

- 1922 - Méthode Decroly7 e Cours de psychologie differréntielle8;

\footnotetext{
${ }^{3}$ Escola de Ensino Especial para Crianças Irregulares, em tradução livre, sendo, na época, consideradas como "crianças irregulares" aquelas que tinham dificuldade ou defasagem de aprendizado ou deficiências mentais.

${ }^{4}$ Do francês, em tradução livre: A pedagogia médica.

${ }^{5}$ Do francês, em tradução livre: As crianças mentalmente anormais do ponto de vista mental.

${ }^{6}$ Do francês, em tradução livre: Em direção a escola renovada.
} 
- 1923 - Fonction de globalisation ${ }^{9}$;

- 1929 - La fonction de globalisation et l'enseignement ${ }^{10}$ e Problemas de psicologia y de pedagogia ${ }^{11}$

Dentre tantos outros trabalhos, Decroly expôs seu método e suas criticas à educação tradicionalista, em busca de melhorias no ensino. Sua última publicação aconteceu em 1932, ano de sua morte, um artigo intitulado Études de psychogenèse ${ }^{12}$.

Ele foi o preconizador do método dos centros de interesse. O método tinha a criança como o centro do ensino e era proposto seguindo três eixos: observação, associação e expressão, sobre os quais serão explanados suas especificidades e modos de utilização mais detalhadamente no decorrer do texto.

Segundo Alberto Munari13 (2010), Jean William Fritz Piaget foi um psicólogo, biólogo e epistemólogo suíço, nascido em 9 de agosto de 1896, na cidade de Neuchâtel e falecido em 16 de setembro de 1980, em Genebra, na Suíça. Ele dedicou sua vida ao estudo da psicologia da evolução da criança, revolucionando conceitos de estudo acerca do intelecto infantil, provocando várias mudanças em antigos conceitos da aprendizagem e da educação.

\footnotetext{
${ }^{7}$ Do francês, em tradução livre: O método Decroly.

${ }^{8}$ Do francês, em tradução livre: Curso de psicologia diferencial.

${ }^{9}$ Do francês, em tradução livre: A Função da globalização.

${ }^{10}$ Do francês, em tradução livre: A função da globalização e do ensino.

${ }^{11}$ Do espanhol, em tradução livre: Problemas de psicologia e de pedagogia.

${ }^{12}$ Do francês, em tradução livre: Estudos de psicogênese.

${ }^{13}$ Alberto Munari, psicólogo e epistemólogo, foi professor da Universidade de Genebra. Doutorou-se em 1971 em Psicologia Genética Experimental, sendo seu orientador Jean Piaget.
} 


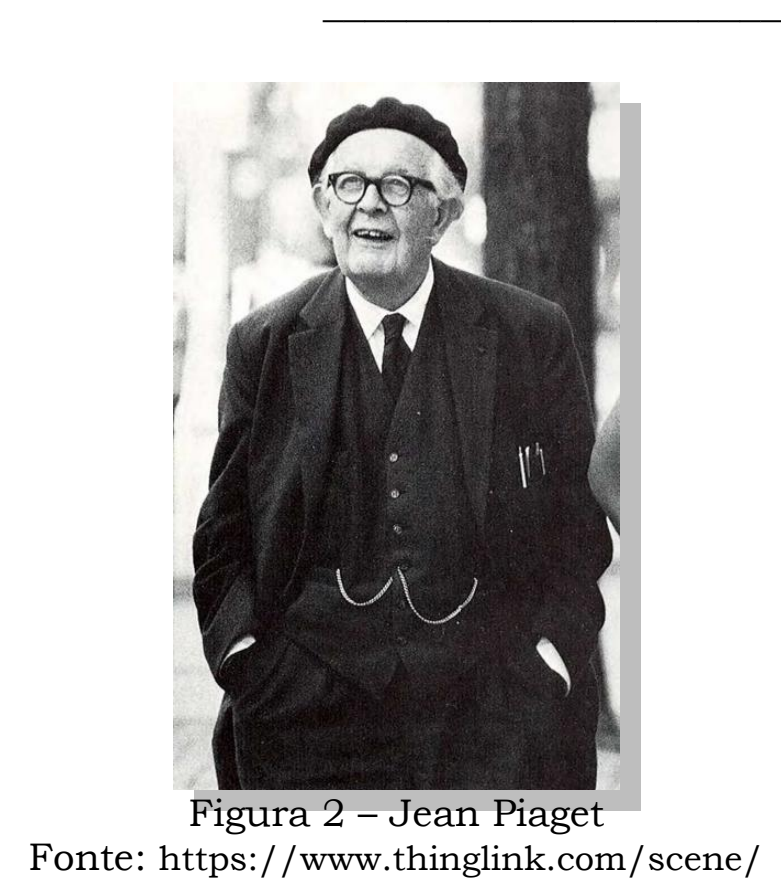

Frazão (2020) relata que "Piaget escreveu cerca de 100 livros e mais de 500 artigos científicos. A metodologia educacional criada por Jean Piaget passou a servir de modelo para diversas escolas em grande parte do mundo". Foi diretor do BIE ${ }^{14}$, de 1929 a 1968. Em cada ano de sua permanência como diretor do BIE, escrevia um discurso que era apresentado ao Conselho e à Conferência Internacional de Instituição Pública. Esses textos ficaram esquecidos pelos estudiosos de sua obra, que embasam os elementos que, em sua essência, mostram a crença do seu fazer pedagógico, ilustrando seus "princípios básicos que orientam seu projeto educacional". (MUNARI, 2010, p. 16). Piaget afirmou: "somente a educação pode salvar nossas sociedades de uma possivel dissolução, violenta ou gradual" (PIAGET MUNARI, 2010, p. 17). Às portas da segunda guerra mundial, ele declarou: "Após os cataclismos que marcaram estes últimos meses, a educação constituirá, uma vez mais, o fator decisivo não só da reconstrução, mas inclusive e, sobretudo, da construção propriamente dita" (PIAGET apud MUNARI, 2010, p. 17), afirmando que a educação da criança é o maior bem das civilizações mundiais.

\footnotetext{
${ }^{14}$ O BIE - International Bureau of Education - Centro Internacional de Educação, ligado à UNESCO, foi fundado no ano de 1925, em Genebra.
} 
Decroly e Piaget - em busca de algumas aproximações

Após esses breves dados biográficos sobre Decroly e Piaget, serão apresentados alguns aspectos da nossa análise baseada em três livros da Coleção Educadores, do Ministério da Educação, de 2010, que versam sobre os mesmos. Essa coleção propõe contribuir para a educação de forma a melhorar sua qualidade e equidade aos niveis de ensino tanto formais como informais, com a cooperação a UNESCO. Fernando Haddad, Ministro da Educação na época em que essa coleção foi organizada, escreve a apresentação dos livros e procura explicitar a importância desse projeto tendo em vista o aprofundamento das politicas educacionais, a necessidade de melhorar a educação do país. Ele explana que, para que esse projeto fosse concretizado, o MEC criou uma comissão técnica, em 2006, composta por representantes do MEC, de pesquisadores do Instituto Paulo Freire e de universidades, com parceria da UNESCO, com o propósito de escolher quais seriam os personagens que fariam parte dessa coleção. Após inúmeras reuniões, optou-se por em uma lista de 30 brasileiros e 30 estrangeiros que tiveram o "reconhecimento histórico e o alcance de suas reflexões e contribuições para o avanço da educação". Quanto ao plano internacional, decidiu-se aproveitar a coleção Penseurs de I'éducation ${ }^{15}$, produzida pelo BIE da UNESCO, a qual inclui obras de Piaget e Decroly. Haddad (2010) destaca, ainda, que o manifesto dos pioneiros foi de grande importância para se pensar nas mudanças na educação que seriam necessárias para, além de atingir a toda a população, também trazer, não só um maior número de pessoas matriculadas nas escolas, mas garantir qualidade da educação escolar e a permanência dos estudantes na escola pública, laica e gratuita de direito a todos os cidadãos.

Segundo Wagnon (2009), que apresenta a introdução do livro Ovide Decroly - Le programme d'une écoledanslavie,

Pedagogos de todo o mundo visam, portanto, um grande público de pais, professores e alunos ansiosos por penetrar neste movimento geral do pensamento e da prática educacional, que

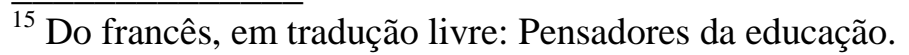


Decroly e Piaget - em busca de algumas aproximações

molda as sociedades e apela para os homens e mulheres de amanhã.

[...]

A pedagogia, muitas vezes considerada como uma disciplina destinada à aplicação de fins educacionais apropriados, abrange um campo de ação que se estende muito além dos limites da faculdade ou do ensino médio. Por meio de suas práticas, informa-nos sobre a forma como uma sociedade se define e enxerga seu futuro econômico, social e político. (WAGNON, 2009, p. 7, tradução nossa)

A apresentação dos educadores, presente nesses três livros utilizados para a sintese deste artigo, leva-nos a perceber que os autores que divulgam essas bibliografias e metodologias são estudiosos e defensores de uma educação inovadora e com fins sociais e igualitários para a sociedade de maneira geral.

\section{Conhecendo as metodologias por onde navegaram nossos ilustres educadores}

Decroly sempre foi contra os métodos tradicionais de ensino, desde pequeno detestou os dois internatos que preconizavam as formações greco-latinas, aos quais foi imposto pelos seus pais. Ele amava a música, desenho e era apaixonado pelas ciências naturais. Criou um método de ensino em busca de melhorar a ensino-aprendizagem de forma significativa e não tradicionalista. Trouxe, para sua casa, crianças chamadas, na época, de anormais ${ }^{16}$, pois acreditava que, com seu método experimental, todas podiam aprender, e que a escola popular, na sua grande maioria, condenava essas crianças à marginalização e ao fracasso, não assegurando sua educação.

Eu afirmo que ela [a escola popular] tem uma influência prejudicial, uma ação antissocial incontestável; ela não só não

\footnotetext{
${ }^{16}$ A Sociedade de Pediatria propôs a Decroly o cargo de médico chefe de uma pequena clínica com o intuito de observar e tratar as crianças ditas "anormais", cargo esse que ele aceitou, mas com a condição de trazê-las como internas para sua casa.
} 
Decroly e Piaget - em busca de algumas aproximações

prepara para a vida, como ela faz de muitos de nós, miseráveis, desclassificados, ou no mínimo, nada faz para evitar isto - o que é a mesma coisa. (DECROLY apud DUBREUCQ, 2010, p. 12).

Decroly afirmava que a escola, da forma tradicional como estava estruturada, poderia ser:

[...] o meio talvez mais potente [de assegurar] a profilaxia da inatividade, da miséria e do crime (...) não como ela está organizada atualmente, uma vez que ela é, em grande parte, a causa direta ou indireta destes males, mas como ela deveria ser organizada, tal como já o é em certos lugares felizes nos quais se compreendeu o que ela pode fazer de mal e o que ela pode fazer de bem. (DECROLY apud DUBREUCQ, 2010, p. 12).

Ele alegava que, onde a família era ruim para com essas crianças, "a proteção médico-pedagógica das crianças vale mais do que 'os hospícios, os asilos, os reformatórios, as prisões (...). São os perniciosos curativos que gangrenam as feridas ao invés de curá-las." (DECROLY apud DUBREUCQ, 2010, p. 12).

Dessa forma, Decroly defendeu a obrigatoriedade da escola, sendo que esse fato só se concretizaria em 1914, sendo realmente efetivada em 1920. Ele denunciou a existência de um monopólio das "humanidades" que se centravam no homem, com fundo em "belas escritas" e cheias de "racionalismo cartesiano limitado ao seu conteúdo filosófico". Defendia o estudo da natureza, sua observação cotidiana de fatos concretos, onde a prática experimental levaria à análise do trabalho humano que transforma a natureza, com o acesso à Ciência. Na busca por um ensino para a educação popular, Decroly se engajou nessas práticas de forma radical e inovadora. 
Decroly e Piaget - em busca de algumas aproximações

Segundo Deubreucq (2010), foi inaugurado, então, em 1901, o "Institut d'éducation spéciale - Laboratoire de psychologie du Dr Decroly"17. As crianças viveram neste lugar recebendo os cuidados necessários, mas, principalmente, uma educação ampla, fazendo com que Decroly, que os observava, amenizar a definição psicométrica da "irregularidade mental". E, diante disso, Decroly afirmou que essas crianças, através dos progressos das mesmas em sua escola experimental, lhe davam embasamento para assegurar que elas podiam ser educadas até mesmo em igualdade com as outras crianças ditas "normais", praticamente no mesmo ritmo e tendo os mesmos limites. O que ele pode comprovar, em 1907, quando alguns pais lhe pediram para aceitar seus filhos: crianças ditas "normais" em uma segunda escola. É fundado, neste ano, o colégio I'Ermitage ${ }^{18}$, localizado o centro da cidade de Bruxelas e transferido, em 1927, para a periferia da mesma cidade.

A metodologia adotada por Decroly baseava-se no que ele denominou de centros de interesse, os quais se estruturavam em três fases: observação, associação e expressão. No primeiro, destacam-se as ciências naturais, geometria e cálculo; no segundo, a história e a geografia e, no terceiro, gramática, trabalhos manuais, linguagem e música. O método global é aquele que vai do todo para as partes. E, essa globalidade se divide em três eixos: a criança e a família; a criança e a escola; a criança e o mundo animal, a criança e o mundo vegetal, a criança e o mundo geográfico e, a criança e o universo.

Decroly sempre afirmou que os centros de interesse não eram uma metodologia terminada, estava sempre em renovação, motivo esse pelo qual não a finalizou. Para levar avante sua escola contou com diversos colaboradores, Boon, Monchamp, Wagnon, Clarinval, Degand, Lamertin, Vermeylen, dentre outros educadores. Ele detalhou as etapas a serem observadas pelos professores e como as colocar em prática, sendo:

\footnotetext{
${ }^{17}$ Instituto de ensino especial - Laboratório psicológico do Dr. Decroly.

${ }^{18}$ Eremitério
} 


\section{A criança e suas necessidades:}

a) precisa se alimentar;

b) precisa lutar contra o mau tempo;

c) precisa se defender contra os perigos e os inimigos diversos;

d) precisa agir e trabalhar, para recriar e melhorar.

2. A criança e seu ambiente: a criança e os animais; [sic]

a) as plantas;

b) a terra: a água, o ar e as pedras;

c) o sol, a lua e as estrelas: [sic]

d) a família;

e) a escola;

f) a sociedade.

Por outro lado, consideramos objetos e fatos de quatro aspectos diferentes:

I. Diretamente por intermédio dos sentidos e da experiência imediata. (I- Exercícios de observação).

II. (II. Exercícios de associação)

a) Indiretamente através da memória pessoal;

b) Indiretamente também pelo exame de documentos diversos relativos aos objetos ou fenômenos atuais, mas não acessiveis;

c) Indiretamente, enfim, pelo exame de documentos diversos relativos aos objetos ou fenômenos passados.

(DECROLY e BOON apud WAGNON 2009, p.142, grifos do autor, tradução nossa)

Decroly recomendava algumas medidas que pudessem remediar as constantes queixas acerca do ensino daquela época, sendo elas:

1) Aplicação de um programa de ideias associadas: estudo da criança e do seu ambiente.

2) Emprego do método dos centros de interesse.

3) Divisão de ramos de ensino, tomando conta das principais funções psicológicas: observação, associação e expressão.

4) Quantidade de conteúdo adequada aos diversos grupos constituídos.

5) Preferência dada aos métodos intuitivos, ativos e construtivos. 
Decroly e Piaget - em 6usca de algumas aproximações

6) Atividade pessoal favorecida pela prática de ocupações manuais (realizações diversas em relação aos centros de interesse) e pelo uso de jogos educativos.

(DECROLY e BOON apud WAGNON 2009, p. 139 e 140, grifos do autor, tradução nossa)

Decroly cria um "Programa de Ideias Associadas e Método de Interesses" que é divulgado, em 1908, na revista Écolenationalle ${ }^{19}$, sendo as carcterísticas deste programa:

$1^{\circ}$ A escola deve responder ao seu objetivo de educação geral, preparando a criança para seu objetivo de educação geral, preparando a criança para a vida social atual;

$2^{\circ}$ Esta preparação realiza-se nas melhores condições, iniciando as crianças praticamente à própria vida em geral e à vida social em particular;

$3^{\circ}$ Esta iniciação no programa requer o exame de duas áreas fundamentais do conhecimento:

O conhecimento da criança de sua própria personalidade; consciência de si mesmo e, portanto, de suas necessidades, aspirações, objetivos e, em última análise, seu ideal;

O conhecimento das condições do meio natural e humano em que vive, do qual depende e do qual deve atuar, para que essas necessidades, essas aspirações, esses objetivos, esses ideais sejam acessíveis, então realizados e sem prejuízo de uma preparação para compreender de forma ampla as necessidades, aspirações, objetivos e ideais da humanidade, as condições para a sua adaptação e os meios para nelas cooperar, para ser solidário com consciência e inteligência. (DECROLY e BOON apud WAGNON 2009, p. 141, grifos do autor, tradução nossa).

Piaget sempre lutou contra as instituições e os preconceitos intelectuais da sua época, até mesmo contra suas crenças em prol da Ciência. Já aos 15 anos de idade, em 1911, publica seus primeiros trabalhos em revistas que tinham uma grande circulação na época. Ele enfatizou que:

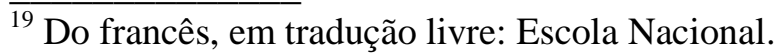


Esses estudos, por prematuros que fossem, foram de grande utilidade para minha formação científica; além disso, funcionaram, poderia dizer, como instrumentos de proteção contra o demônio da filosofia. Graças a eles, tive o raro privilégio de vislumbrar a ciência e o que ela representa antes de sofrer as crises filosóficas da adolescência. Ter tido a experiência precoce destes dois tipos de problemática constituiu, estou convencido, o motivo secreto da minha atividade posterior em psicologia. (PIAGET apud MUNARI, 2010, p. 13).

Vários autores escreveram sobre as contribuições de Piaget para as práticas educacionais ${ }^{20}$, mesmo o próprio autor tendo apenas $3 \%$ de suas obras voltadas para essa premissa, teve uma importante relevância para o estudo dessas práticas.

Piaget não se considerava um pedagogo, mas muito fez para se entender o processo cognitivo da criança. Acreditava que "o método científico era a única via de acesso legítima do conhecimento" (MUNARI, 2010, p.13). Segundo ele, os métodos reflexivos e/ou filosóficos contribuintes em alguns tipos de conhecimento apenas. Afirmou, acerca da psicologia, que "Isso me fez adotar a decisão de consagrar minha vida à explicação biológica do conhecimento.” (PIAGET apud MUNARI, 2010, p. 13).

Piaget, no que concernia a sua vida profissional, era pesquisador e professor universitário, com forte inquietação quanto a ser reconhecido pelos seus pares, o que o estimulou e o orientou por toda sua vida (MUNARI, 2010, p. 14). Ele trabalhou, em Paris, com Janet, Piéron e Simon nos laboratórios que Binet fundou, descobrindo, então, quão rico é o

\footnotetext{
${ }^{20}$ Algumas referências clássicas que tratam as obras piagetianas: Campbell \& Fuller, 1977; Copeland, 1970; Duckworth, 1964; Elkind, 1976; Forman \& Kuschner, 1977; Furth, 1970; Furth \& Wachs, 1974; Gorman, 1972; Kamii, 1972; Kamii\& De Vries, 1977; Labinowicz, 1980; Lowery, 1974; Papert, 1980; Rosskopf et al., 1971; Schwebel \& Raph, 1973; Sigel, 1969; Sinclair \& Kamii, 1970; Sprinthall \& Sprinthall, 1974; Sund, 1976; Vergnaud, 1981.
} 
Decroly e Piaget - em busca de algumas aproximações

pensamento da criança, tendo elaborado seu primeiro rascunho do seu método crítico, ou clínico ${ }^{21}$.

No início, Piaget buscava associar três métodos já utilizados na tradição ocidental: método empírico das ciências experimentais, o método hipotético-dedutivo das ciências lógico-matemáticas e o método históricocrítico das ciências históricas (MUNARI apud MUNARI, 2010, p. 15). Nesse momento, trabalhou com crianças hospitalizadas. Somente quando foi chamado à Genebra, por Claparède ${ }^{22}$ e Bovet ${ }^{23}$, iniciou seu estudo acerca da criança em seu "habitat normal" e, principalmente, na escola. Seu principal campo de pesquisa se tornou a Casa das Crianças do Instituto Jean-Jacques Rousseau. Desta época em diante, Piaget se dedi-cou ao estudo do desenvolvimento e aperfeiçoamento dos sistemas de educação e de suas práticas. Como diretor do BIE, em seus discursos anuais, como primeira regra fundamental para a educação alertou que "A coerção é o pior dos métodos pedagógicos." (PIAGET apud MUNARI, 2010, p. 17). Piaget defendia também que, "no terreno da educação, o exemplo deve desempenhar um papel mais importante do que a coerção" (PIAGET apud MUNARI, 2010, p. 17) e, ainda, uma "verdade aprendida não é mais que uma meia verdade, enquanto a verdade inteira deve ser reconquis-tada, reconstruída ou redescoberta pelo próprio aluno." (PIAGET apud MUNARI, 2010, p. 17 e 18). Essas eram as bases que Piaget sustentava, na qual o aluno tinha papel ativo na sua educação. Ele alegava que:

Não se aprende a experimentar simplesmente vendo o professor experimentar, ou dedicando-se a exercícios já previamente organizados: só se aprende a experimentar, tateando, por si mesmo, trabalhando ativamente, ou seja, em liberdade e dis-

\footnotetext{
${ }^{21} \mathrm{Ou}$ seja, o método clínico, "de interrogação da criança, partindo de uma síntese totalmente original e surpreendente dos ensinamentos que acabara de receber de Dumas e Simon, em psicologia clínica, e de Brunschvicg e Lalande, em epistemologia, lógica e história das ciências". (MUNARI, 2010, p. 14).

${ }^{22}$ Edouard Claparède foi um neurologista e psicólogo do desenvolvimento infantil, se especializando na pedagogia e formação da memória. Nasceu em 24 de março de 1873, em Genebra, Suíça, e faleceu em 29 de setembro de 1940, em Genebra.

${ }^{23}$ Pierre Bovet, psicólogo e pedagogo, nasceu em 5 de junho de 1878, em Boudry, na Suíça, e faleceu em 2 de dezembro, também, em Boudry.
} 
Decroly e Piaget - em 6usca de algumas aproximações

pondo de todo o tempo necessário. (PIAGET apud MUNARI, 2010, p. 18)

Segundo Piaget, "É muito mais fácil raciocinar do que experimentar". Os métodos ativos são necessários tanto para crianças quanto adultos, pois, como afirma Piaget, "cada vez que o adulto aborda problemas novos, o desenvolvimento de suas reações assemelha-se à evolução das reações do desenvolvimento mental." (PIAGET apud MUNARI, 2010, p. 19).

Piaget, quanto às diversas disciplinas, forneceu recomendações no que concerne ao ensino de Matemática. Apontou que uma educação sensório-motora, exemplificando "a Casa das Crianças em Genebra, favorece a iniciação à matemática” (PIAGET apud MUNARI, 2010, p. 19), era mais desenvolvida na criança do que a lógica verbal.

Piaget não acreditava no fracasso com relação à Matemática, afirmando que a falta de aptidão não seria o motivo do fracasso dos alunos nessa disciplina. Ainda apontava que a Matemática se deriva da ação, não bastando a intuição para esse aprendizado. "Em todos os domínios da matemática, o qualitativo deve preceder ao numérico." (PIAGET apud MUNARI, 2010, p. 19), sendo de suma importância a operação manual antes da mental, portanto:

É necessário estabelecer entre as crianças, sobretudo entre os adolescentes, relações sociais, apelar para a sua atividade e para a sua responsabilidade. (PIAGET apud MUNARI, 2010, p. 20).

Nos seus vários discursos, quando se referia às relações entre Educação e Psicologia, ele assegurava que esta relação é necessária:

Não creio que exista uma pedagogia universal. O que é comum a todos os sistemas de educação é a própria criança, ou pelo menos, algumas características gerais de sua psicologia. (PIAGET apud MUNARI, 2010, p.20). 
Decroly e Piaget - em busca de algumas aproximações

Piaget afirmava que foi a partir dos estudos investigativos da Psicologia que surgiram as novas metodologias de ensino da época, salientando:

É inegável que as investigações dos psicólogos foram o ponto de partida de quase todas as inovações metodológicas e didáticas destas últimas décadas. Nunca é demais recordar que todos os métodos que apelam aos interesses e à atividade real dos alunos se inspiraram na psicologia genética. (PIAGET, apud MUNARI, 2010, p. 20).

Piaget também alegava que são complexas essas relações da Pedagogia e Psicologia, sendo a primeira uma arte e a segunda uma ciência. Em suas análises afirmava que a Pedagogia experimental não poderia existir sem a Psicologia.

Se a psicologia experimental quer ser uma ciência puramente positivista, ou seja, que se limita a constatar fatos e não pretende explicá-los, que se limita a constatar resultados, mas sem compreender suas razões, é evidente que não necessitará da psicologia. [...] Mas se a pedagogia experimental quer compreender o que descobre, explicar os resultados que encontra, explicar as razões da eficácia de certos métodos em comparação com outros, neste caso, com certeza, é indispensável relacionar a pesquisa pedagógica com a investigação psicológica, isto é, praticar constantemente a psicopedagogia, e não simplesmente adotar as medidas de rendimento da pedagogia experimental. (PIAGET apud MUNARI, 2010, p.21).

Piaget, por vários anos, se dedicou ao que mais o fascinava desde o início de sua carreira: estabelecer "uma espécie de embriologia da inteligência." (PIAGET apud MUNARI, p. 22). Estudou a evolução da inteligência de diversas maneiras e por diferentes especialidades.

A aprendizagem significativa, formulada por Piaget (por mais que ele afirmasse que não era uma metodologia, que não estava pronta), se baseava na assimilação, acomodação, adaptação e equilibração. Essas 
Decroly e Piaget - em 6usca de algumas aproximações

quatro fases são os processos do desenvolvimento cognitivo de Piaget. Munari (2010, p. 30) indica que: "Se chamarmos acomodação ao resultado das pressões exercidas pelo meio, podemos então dizer que a adaptação é um equilíbrio entre a assimilação e a acomodação". Sendo, na acomodação, que se dá o desenvolvimento cognitivo. A assimilação é tida por ele como a própria inteligência, pois engloba os dados da experiência e também Piaget afirma que ela não pode ser pura, pois, quando abarca componentes novos, a inteligência transforma os últimos para adequá-los às informações recentes. Na adaptação, ela é, em suas palavras, "uma equilibração progressiva entre um mecanismo assimilador e uma acomodação complementar" (MUNARI, 2010, p. 31), e só existe quando a acomodação é perfeita. Sendo a inteligência um caso particular de adaptação biológica, pois, para entender a vida de uma forma geral, "é necessário determinar quais as relações que existem entre o organismo e o meio ambiente". Já, a acomodação consiste nas modificações estruturais do pensamento humano em permanente modificação.

As teorias do construtivismo genético, a descrição dos estágios de desenvolvimento da criança e dos conhecimentos científicos foram os marcos históricos de Piaget, que voltaram para as práticas educacionais, de acordo com alguns autores que estudaram essas teorias. Piaget formulou uma hipótese que denominou "paralelismo", que tinha enfoque no estudo da inteligência entre "os processos de elaboração do conhecimento individual e os processos de elaboração do conhecimento coletivo, ou seja, entre a psicogênese e a história das ciências." (PIAGET; GARCIA apud MUNARI, 2010, p. 22). Esta hipótese foi palco de muitas controvérsias, transcendendo a região de Genebra, e inspirando uma enorme gama de trabalhos científicos do Centro Internacional de Epistemologia Genética ${ }^{24}$, o que deu abertura ao debate acerca da educação inspirada em Piaget.

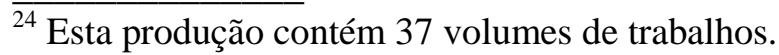


Decroly e Piaget - em 6usca de algumas aproximações

Piaget apoiou os métodos ativos, preconizados por Montessori25, Freinet ${ }^{26}$, Decroly e Claparède. E, assim, ele se inseriu nas práticas escolares, mesmo não sendo esse seu foco de pesquisa.

Resumidamente, são esses os princípios dos métodos experimentais dos autores analisados em nossa pesquisa. A seguir, discorremos sobre certas correspondências que encontramos entre eles.

\section{Algumas aproximações entre Decroly e Piaget}

Tanto Piaget quanto Decroly tiveram dificuldades em aceitar as instituições tradicionalistas e os preconceitos da intelectualidade da época em que viveram. Não tinham apreço pelos métodos tradicionais, sendo que ambos defendiam que o ensino não deveria se basear em decorar os conteúdos, nem repetitivo e nem ditatorial, mas sim algo que podia se tornar interessante e instigante para o aluno. Esses dois psicólogos e educadores possuem, em suas teorias, alguns elementos em comum em suas pesquisas, publicações e debates. Os dois afirmam que o aprendizado da criança não é linear.

Eles também não concordavam que os meios coercitivos no processo de ensino aprendizagem auxiliavam que os alunos adquirissem conhecimento. Na verdade, seria mais um elemento a atrapalhar a educação e formação do sujeito como um ser crítico e constituinte de seu próprio aprendizado.

Para Piaget,

\footnotetext{
${ }^{25}$ Maria Tecla Artemisia Montessori foi uma educadora, médica e pedagoga italiana. Desenvolveu um método com ênfase na autonomia, liberdade e respeito, para o desenvolvimento físico e mental das crianças. Nasceu em 31 de agosto de 1870 e faleceu em 6 de maio de 1952.

${ }^{26}$ Célestin Freinet foi um pedagogo e pedagogista francês. Sua pedagogia se fundamenta em quatro eixos: cooperação; comunicação; documentação e afetividade. Nasceu em 15 de outubro de 1896, em Gars França e faleceu em 8 de outubro de 1966, em Vence, França.
} 
Decroly e Piaget - em 6usca de algumas aproximações

A principal meta da educação é criar homens que sejam capazes de fazer coisas novas não simplesmente repetir o que outras gerações já fizeram. Homens que sejam criadores, inventores, descobridores. A segunda meta da educação é formar mentes que estejam em condições de criticar, verificar e não aceitar tudo que a elas se propõe. (PIAGET apud MUNARI, 2010).

Decroly defendia, de maneira semelhante, que a criança deveria escolher o que aprender e, partindo dessa escolha, seu professor mediaria essa aprendizagem. A criança precisa ter interesse pelo que vai estudar, ser o centro da educação partindo da sua curiosidade e, daí, partindo do todo para as partes o educador a guiaria. Corroborando com Decroly, as propostas de ensino piagetianas têm como norte o fato de o professor ser um mediador e não um mero expositor, proporcionando aos alunos problematizações para que o mesmo seja capaz de criar e não só decorar (DUBREUCQ, 2010).

Piaget (apud MUNARI, 2010) afirmava que o "professor não ensina, mas arranja modos de a própria criança descobrir. Cria situaçõesproblemas". Logo, os dois estudiosos corroboram na premissa de mediação que o professor deve utilizar.

Piaget (apud MUNARI, 2010, p. 17) salientava que "O bem comum de todas as civilizações: a educação da criança"; enquanto Decroly também inferia que a criança deve ser o centro do ensino.

Pode-se dizer que as idéias de Decroly e Piaget estiveram presentes no contexto da vaga pedagógica da Escola Nova, buscando e aspirando mudanças na educação através de seus experimentos, pesquisas e metodologias (embora Piaget não se considerasse um pedagogo).

Outro elemento em comum entre os dois é no que concerne ao estudo da Matemática. Decroly acredita que a Matemática se consagra co- 
Decroly e Piaget - em 6usca de algumas aproximações

mo ferramenta universal, o que aproxima as ciências ou técnicas (DUBREUCQ, 2010, p. 47). Piaget afirma que o problema da dificuldade matemática vem das metodologias utilizadas racionalmente e que esse problema teve mudanças em consequência das transformações das próprias matemáticas. Os dois concluem que é uma disciplina de não-fácil discernimento, mas, em processo concreto, o aprendizado se torna mais significativo.

Piaget (apud MUNARI, 2010, p. 16) infere que: "a adoção oficial de técnicas melhor adaptadas ao espírito infantil" é necessária para que se faça realmente com que a criança aprenda. Munari (2010) ainda afirma que:

O Piaget epistemólogo propunha outro ponto de vista e sugeria descentrar, de alguma maneira, o aluno de seu nivel, de suas dificuldades, de suas habilidades particulares, para abrir-se mais ao seu contexto cultural e levar em conta os diversos percursos e trajetórias históricas dos conceitos a que se propõe estudar ou fazer estudar. (MUNARI, 2010, p. 23).

\section{Considerações finais}

Neste artigo, um dos objetivos foi apresentar algumas aproximações entre o método global dos centros de interesse de Decroly e o estudo experimental de Piaget. Nossa análise evidencia que os dois tinham práticas e crenças em comum e uma das grandes aproximações encontradas foi que ambos preconizavam a criança como foco central dos seus estudos, em busca de que se concretizasse uma educação de forma qualitativa, formando cidadãos capacitados e com senso crítico. Uma educação nada tradicional, mas focada na vida do sujeito como construtor do seu conhecimento e desenvolvimento de seu aprendizado, tendo no educador um mediador e auxiliar nesse processo de ensino.

Com embasamento nessa primeira pesquisa, salientamos que há necessidade de maiores investigações na busca de pontuar de modo mais 
Decroly e Piaget - em 6usca de algumas aproximações

pormenorizado as aproximações preliminares descritas neste artigo. Para trabalhos futuros, é fundamental um maior número de referências, tanto livros, como artigos em revistas e jornais, que envolvam esses dois precursores de uma nova visão do ensino e cognição humana da psicologia experimental e educacional.

\section{Referências}

DUBREUCQ, Francine. Jean-Ovide Decroly. Tradução de Carlos Alberto Vieira Coelho, Jason Ferreira Mafra, Lutgardes Costa Freire e Denise Henrique Mafra. Recife: Editora Massangana/Fundação Joaquim Nabuco, 2010. (Coleção Educadores).

FRAZÃO, Dilva. Jean Piaget. 2020.

Disponivel em: https://www.ebiografia.com/jean_piaget. Acesso em: 17 abr. 2021.

HADDAD, Fernando. Apresentação. In: MUNARI, Alberto. Jean Piaget. Tradução de Daniele Saheb. Recife: Editora Massangana/Fundação Joaquim Nabuco, 2010. (Coleção Educadores).

MUNARI, Alberto. Jean Piaget. Tradução de Daniele Saheb. Recife: Editora Massangana/Fundação Joaquim Nabuco, 2010. (Coleção Educadores).

WAGNON, Sylvain. Ovide Decroly: Le programme d'une école dans la vie. Paris: Éditions Fabert, 2009. (Collection Pédagogues du Monde Entier).

Artigo recebido em: 3 maio 2021 Artigo aprovado em: 20 jun. 2021 